\title{
Building the Platform of Teacher Professional Development for Teachers in Vocational College to Convert Tacit Knowledge
}

\author{
Caixia Wang \\ Information and Technology College \\ Tianjin University of Technology and Education \\ Tianjin, China \\ wcx14@126. Com
}

\begin{abstract}
Due to the particularity of vocational education, vocational colleges teacher had a lot of tacit knowledge in skill, which was very difficult to be coded, summed and expressed. The platform was built to promote the conversion of tacit knowledge and improve teacher professional development by some tools and technology. The structure of the platform used $\mathrm{B} / \mathrm{S}$ mode, and there were some functional modules which were Resource Database, Teacher Studio, Teaching Activities Room and Watching the Video Room. The platform had been developed by Microsoft Visual Studio 2010, C\#. Net and Microsoft SQL Server 2008.
\end{abstract}

Keywords- tacit knowledge ; the Platform of teacher professional development; knowledge conversion; vocational colleges;explicit kowledge

\section{INTRODUCTION}

Vocational education was professional education to train professionals in the field of vocation, which emphasized on practical training, skill and technical education. ${ }^{[1]}$ In order to achieve the goals of the vocational education, teacher of vocational colleges had not only theoretical knowledge, but also professional skill, which was called "Doubleprofessionally-titled Teachers". Double-professionally-titled Teachers of vocational education had a lot of tacit knowledge, and it was only required to convert tacit knowledge in order to raise teachers' professional level. With information in vocational education, it was very necessary for the teacher of the vocational colleges to develop the platform of teacher professional development according to their features.

\section{CONSTRUCTION CONCEPT OF THE PLATFORM}

Teacher knowledge was divided into teacher explicit knowledge and teacher tacit knowledge in this study. Explicit knowledge of the teacher was able to clearly express, exchange and storage. Teacher' Tacit knowledge was deeply rooted in mind, included ideas, emotion, cognition, teaching organization management capacity, teaching methods, teaching skill, etc. This knowledge was difficult to express, exchange and storage. Double-professionally-titled Teachers of vocational education had a lot of tacit knowledge which was skill. According to the knowledge conversion theory proposed by the famous scholar Nonaka and Takeuchi, teacher' knowledge conversion was shown in figure 1.

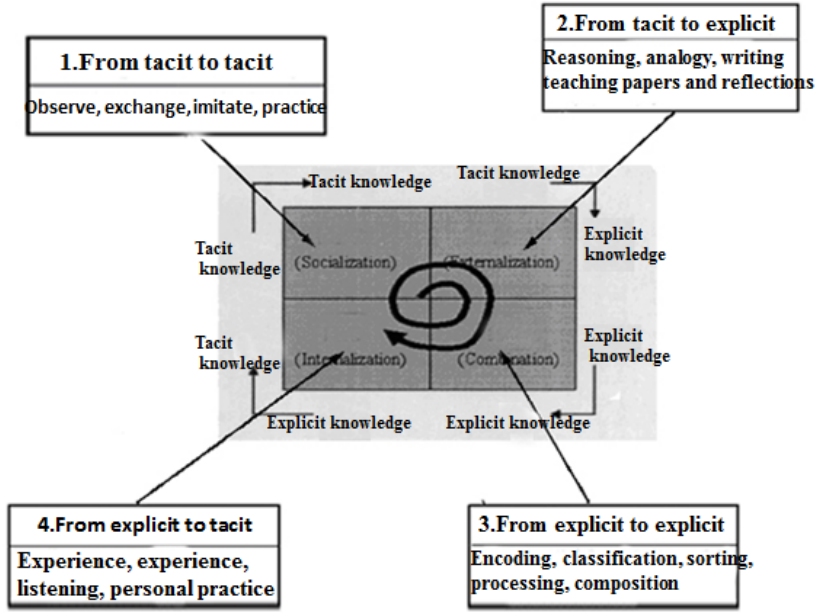

Figure 1 teacher’ Knowledge Conversion

From above figure, teacher' tacit knowledge was transformed through socialization and internalization.

Socialization of knowledge achieved the knowledge conversion from tacit knowledge to tacit knowledge by discussion, watching instructional videos, listening to the lectures of outstanding teachers. Internalization of knowledge realized the knowledge conversion from explicit knowledge to tacit knowledge by "Learning by doing", which teacher Learned and thought excellent teaching experience, and used them in the actual teaching.

\section{THE WHOLE STRUCTURE OF THE PLATFORM}

The structure of the platform used B/S mode, the user's interface of the platform was divided into teacher interface, expert interface and the administrator interface. The platform used the common mode of three-hierarchy: application layer, service layer and data layer, and the hierarchy were explicit. The platform provided with intelligent agent service, when the user send a request to the Web server through the browser, the web server communicated with intelligent agent after the requisition of user were received, then the requisition was delivered to the Web server and returned to the users, through intelligent agent obtaining information from the database. Other programs of the platform were called by the user through web server. The whole architecture of the platform was shown in figure 2 . 


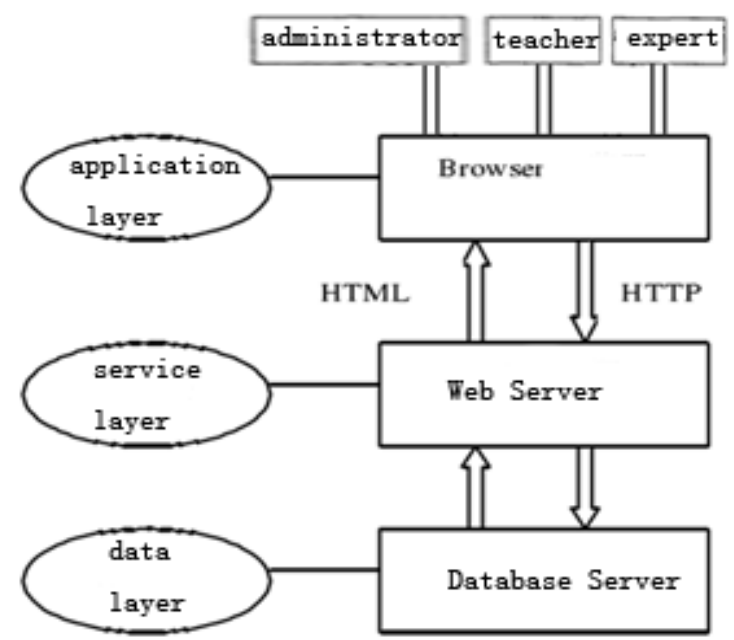

Figure 2 The architecture of the platform

\section{DEVELOPMENT ENVIRONMENT AND TOOLS OF THE PLATFORM}

Development environment and tools of the platform were following:

1) Software of web server in the platform was IIS7.0, in order to provide the basic Web services function, which was characterized by a simple and quick to deploy and easy-touse maintenance.

2) The development tools were Microsoft Visual Studio 2010, and scripting language of server-side was C\#. Net, which were the visual development interface and rapid development model.

3) Database of the platform was Microsoft SQL Server 2008, which was convenient to develop and maintain.

4) The platform used FCKEditor which was online editing component. This component was the text editor which was applied in web page by open source, and it was very simple to install.

\section{THE MAIN FUNCTIONAL MODULES OF THE PLATFORM}

Based on the above structure concept, the platform would achieve the storage of knowledge, externalization and internalization of tacit knowledge. Functional modules of the platform included Resource Database, Teacher Studio, Teaching Activities Room and Watching the Video Room, and each module had some specific operating. It was shown in figure 3.

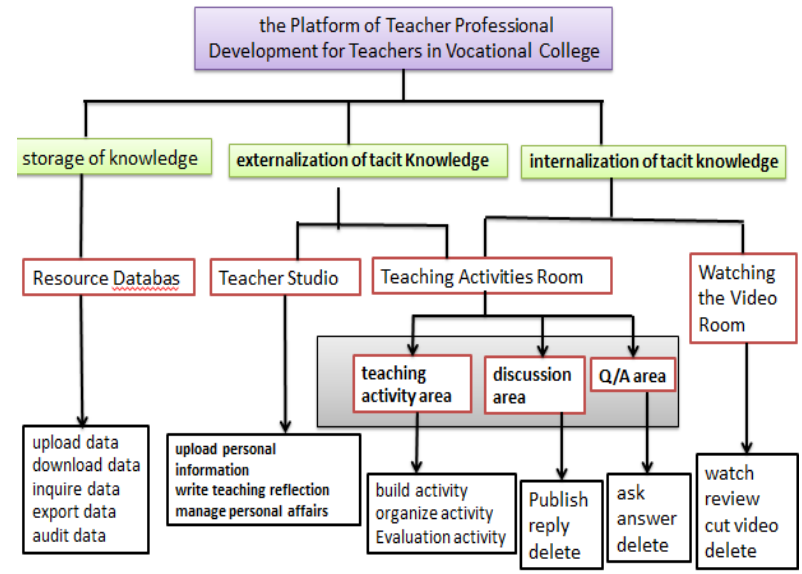

Figure 3 the structure of functional modules

The system of platform was designed in accordance with applications and responsibilities of the identity, roles and authority. Identity was divided into registered user and system administrator. Registered users had expert and teacher, who would dynamically play different roles in the platform. Different identities of the users had specific operating authority in different module. As the following:

\section{A. Resource Database}

According to the process of knowledge management, knowledge conversion was implemented, after the information was obtained. Resource Database provided teaching resources for the teacher, in order to quickly obtain knowledge. A resource of Resource Database was classified stored in accordance with the curriculum and the form of resources, and title and introduction could be listed by searching keywords. In addition, the resources of Resource Database were regularly pushed to the Teacher Studio according to teacher information. Operation authority of user in the Resource Database was shown in figure 4.

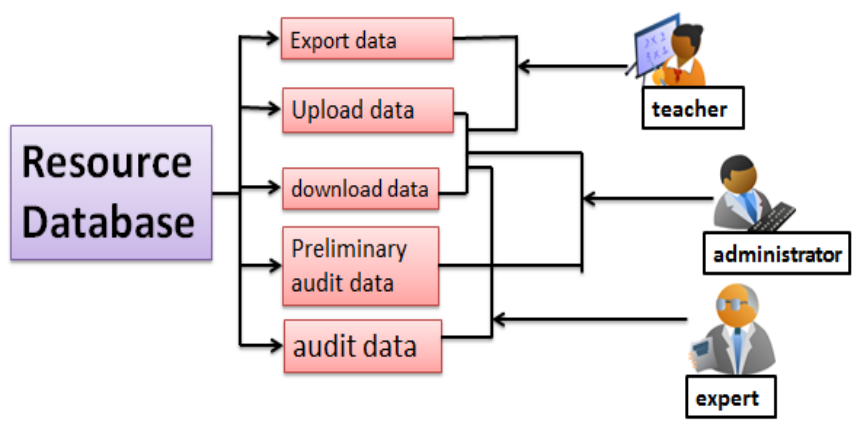

Figure 4 Operation Authority of User in the Resource Database

In Resource Database, administrator could upload the specified data which was appointed by expert and teacher, and examine the data uploaded by other users. When the information which was useful for teaching was examined by 
administrators, it was directly deleted, thus reducing the workload of expert.

Teacher users could upload and query data in Resource Database, thus find the teaching materials; meanwhile the data could be downloaded to the local computer.

The operation authority of the expert user in the Resource Database module could audit the data. After other users uploaded the data, it was not presented in the interface of Resource Database, but stored in the special temporary database. The experts could see the data in the temporary database after expert logged in, and audited the data. The data could be pretended in the interface of Resource Database through expert auditing. The expert could also upload and download the data in Resource Database, and recommend some video information to skill broadcasting hall.

\section{B. Teacher Studio}

Teacher Studio mainly achieved externalization of tacit knowledge for teacher, which was private space of teacher, expert and administrator could only view. Teacher Studio provided web writing space for teacher, where teacher could write teaching reflective blog, collect the data of education theory, and accumulate their own teaching sentiment.

Teacher Studio provided the functions of daily affairs management for the teacher, where there was the schedule time to record the teacher's own learning trajectory by the main line. The teacher could manage personal blog and resources by date or category. In addition, the studio provided scheduling, address book management and remind of day-to-day affairs for teacher.

\section{Teaching Activities Room}

Resource Database had a lot of resources, and the data could reflect the value of itself after it was transformed into knowledge. The Teaching Activities Room was the core modules of the platform, which could support externalization and internalization of tacit knowledge. The module would be able to carry out a series of teaching and research activities. Teacher, expert and administrator had operated authority. It was shown in Figure 5.

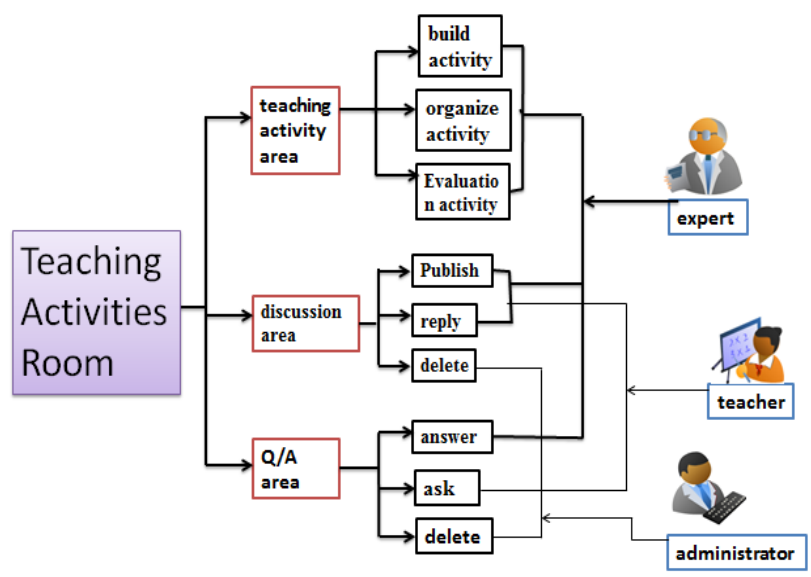

Figure 5 Operation authority of User in the Teaching Activities Room
Expert users could initiate teaching activities according to the needs of teaching and post in Bulletin Board. Teaching activities included preparing for lessons together, watching teaching and theoretical discussion, which teacher was interested in the topic. After the release of the activity, expert at the same time announced the related resource in Resource Database, and teacher downloaded and read. Then, expert organized teacher and let teacher discuss issues in the forum, and expert could be asked by Q \& A area. After the end of the discussion activity, expert summarized the results of the activities, and proposed evaluations for every person who participated in activities.

In Teaching Activities Room, teacher who was a member of activity, viewed notifications and read the data recommended by expert, then expressed their views in the forum, where teacher could share point and ideas. In addition, teacher could ask through Q \& A area and expert answer them.

The operating authority of administrator in this module was relatively small, mainly deleted remarks which were unrelated to teach according to the requisition of the expert and teacher.

\section{Watching the Video Room}

The video of Watching the Video Room was audited and recommended by expert. These video rendered the content of training-practice courses, which truly recorded and reproduced the teaching scene, to show the operation of the skill and convey how to use practical knowledge to cope with teaching perplexity, meanwhile demonstrated teaching methods, technology applications, problem-solving. In the Watching the Video Room, teacher could write their feelings and experiences to achieve internalized of tacit knowledge through watching video by online.

In this module expert and teacher had the same operation authority, who could watch video and discuss.in addition, experts and teachers used the cutting tool of video to cut video according to the needs of watching, and then the cut video was repeated playback.

In this module, operation authorities of administrator only viewed and delete reviews which had nothing to do with teaching.

\section{CONCLUSION}

According to the particularity of the vocational education, it was crucial to convert tacit knowledge in the platform of teacher professional development for teachers in vocational college. In this platform, the expert organized the various forms of activities about teaching and research by the tools provided by the platform, to create good atmosphere for the exchange and sharing, mobilize the enthusiasm of the teacher. Conversion of tacit knowledge was reached through writing teaching blog and watching teaching video, etc. In result, teachers' professional level was raised. The platform had been developed, and it would be improved and optimized in the process of the application according to some recommendations, in order to provide good services for teachers' professional development of vocational colleges. 


\section{ACKNOWLEDGMENT}

This study was funded by "development and application of the platform of teacher professional development for teachers in vocational college" which was research development fund project of Tianjin University of Technology and Education (project number: KJ10-14) and "the theory and practice of information technology optimizing classroom teaching in vocational instruction " that was key project of the Ministry of Education on National Education Science Plan " the 11th Five-Year Development Guidelines " (project number:GJA094016). Thank you very much for this study to provide funds, and also thank the other members of the research group. In the course of the study, some literature was referred, thank the authors.

\section{REFERENCES}

[1] Baidu Library, "The Characteristics of Vocational Education", http://wenku.baidu.com/view/d702e3fa910ef12d2af9e780.html 2012.11.

[2] J.P.Zhao, "Do Better Knowledge Management for Teacher Working Efficiently, " Modern education technolodge,2003,(5):68-71 .

[3] C.X.Wang, "The Study of Teacher Knowledge Management Based on the Digital Library of Primary and Secondary School, " Master Degree thesis , Capital Normal Univercity, 2009.

[4] X.Y.Wu,Y.Liu, "The Function Design of the System about Teacher Personal Knowledge Management," China educational technology,2011(1):129-132 .

[5] M.Y. Chen, "Learning and Professional Development of Teachers from the Point of View of Tacit Knowledge, "Course and teaching. Tai-Wan, Chinese, 2006.

[6] Yu-Hao Kate Lin ,MingDao, "Teachers' Personal Knowledge Management:Theoretical Foundations and Building Blocks, " http://www.ifla.org/IV/ifla71/papers/066e-Chaudhry.pdf

[7] "Knowledge Sharing Practices in Asian Iinstitutions: a Multi-cultural Perspective from Singapore, " http://www.atee2007.org.uk/docs/LinYHK.doc.

[8] J. F. Rong, J. Y. Hung \&F. C. Cheng, "A Study of the Vocational Teachers' Knowledge Management Platform, " Proceedings of the International Conference on Computers in Education (ICCE’02) . 